\title{
66. SMECTITE DISTRIBUTION, LEG 37 BASALTS
}

\author{
J.F. Fischer, Department of Geology, University of Texas, Arlington, Texas
}

\section{INTRODUCTION}

Smectites occur in practically all of the basalts recovered on Leg 37 . The amounts are highly variable: a very few specimens are virtually free of the clay mineral, while others contain $15 \%$ or $20 \%$. The average is probably around $5 \%$. Some of the rocks with abundant smectite have virtually unaltered olivines, while others have apparent pseudomorphs of clay or clay and carbonate after olivine. This study was undertaken to determine what parts of the rock texture are replaced by the smectite and to speculate on the smectite origin. A possibility that was carefully considered is the possible presence of chlorophaeite; no evidence was found to substantiate the formation of this material in these basalts. The conclusions in this paper are based on optical examination of most of the 300 thin sections made during the Leg 37 cruise.

\section{PRIMARY TEXTURES}

Textures in the Leg 37 basalts range from subophitic to glassy. The subophitic or microdoleritic textures are restricted to thicker, massive units without intervening glassy rinds, which are probably massive flows or sills. The rocks with abundant glassy rinds, and therefore probably from pillow sequences, have textures ranging from intergranular, with about $15 \%$ glass, through variolitic to glassy, with about $2 \%$ crystals. These differences are thought to relate to position within individual pillows and to pillow dimensions. The glassy patches of the more fully crystallized interiors commonly range up to $120 \mu \mathrm{m}$ long; they are usually dark brown, and contain skeletal magnetite crystals, rare globular sulfides, and fibrous unidentified crystallites (see Figures 1,2). In addition many of the rocks are slightly diktytaxitic, in that they contain $5 \%$ or more void space. The voids occur both as microvesicles in the glass and as microlite-bounded interstitial gaps (see Figures 3, 4). All of the rocks, even the coarsest grained, show traces of variolitic sheaves.

Basalts with subophitic textures form the minority. The crystals average about double the size of those in the pillows, and the magnetites are more often chunky, equant crystals than feathery skeletons. Primary textures are strongly diktytaxitic, with about $15 \%$ void space and about $10 \%$ pinkish-brown glass plus crystallites. Isolated variolitic sheaves of plagioclasepyroxene suggest an initial rapid cooling; this could have happened either by extrusion onto the sea floor, or intrusion into a pillow pile with an active cold seawater circulation system.

\section{SMECTITE DISTRIBUTION}

In the intergranular-textured rocks, the smectites characteristically occur in bands which only poorly conform with obvious vein orientations. The smectites are not restricted to near the vein, either; they often occur in narrow bands ( 1 to $2 \mathrm{~mm}$ wide) at a distance of at least $1 \mathrm{~cm}$ from the fracture surface. Such bands are bounded on both sides by rock which optically appears unaltered, yet the bands join and split with other similar bands. They are similar in appearance to diffusion bands (see Figure 5).

The smectites occupy two, and possibly three, different parts of the rock texture. Some are spacefilling. They normally fill the entire cavity of the small, diktytaxitic openings (see Figure 6) and form linings of variable thicknesses in the vesicles $(0.1 \mathrm{~mm}$ and larger); less commonly they fill the vesicles completely. Particularly in the microvesicles within glass patches these globular smectite fillings give the initial impression of a replacement of a preexisting immiscible phase (see Figures 1, 7).

Smectites also replace the glass. Some of these replacement smectite patches are not as clear and even as the space filling smectite. They have skeletal magnetite and the fibrous material as inclusions (see Figure 8), and often also contain patches of abundant minute dark brown spots.

In one band the smectite patches contain geometric patterns with shapes of plagioclase and pyroxene microlites. In this rock, there is a possibility that the smectites also replace the microlites of the rock. These patches are larger than any other glassy or irregularly shaped glass and vesicle areas elsewhere in the thin section. Such relationships were not found elsewhere, however.

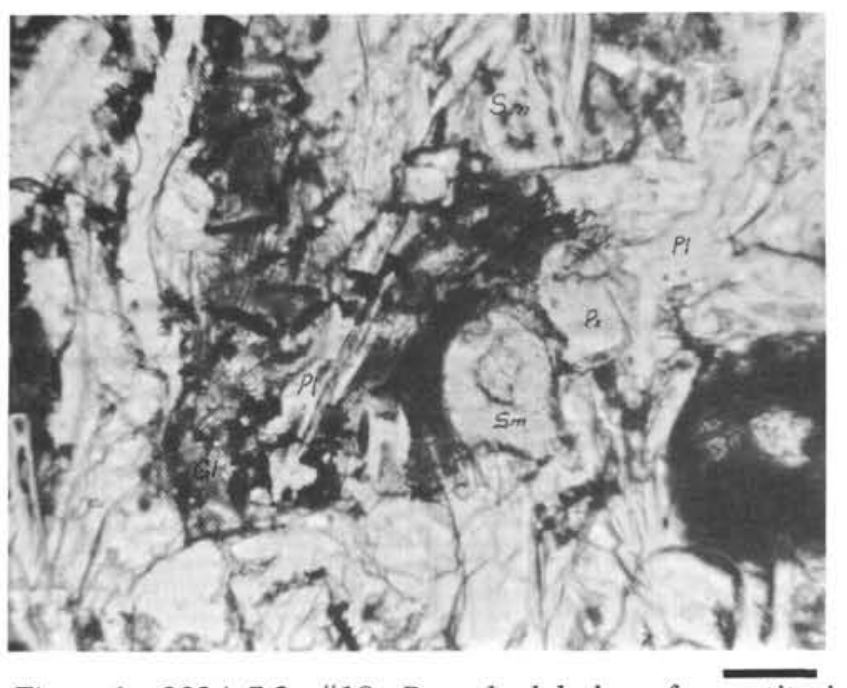

Figure 1. 332A-7-2, \#18. Round globules of smectite in dark magnetite and fiber-filled glass. G1-glass; P1-plagioclase; Px-pyroxene; Sm-smectite. Bar scale is $0.02 \mathrm{~mm}$ long. Plane light. 


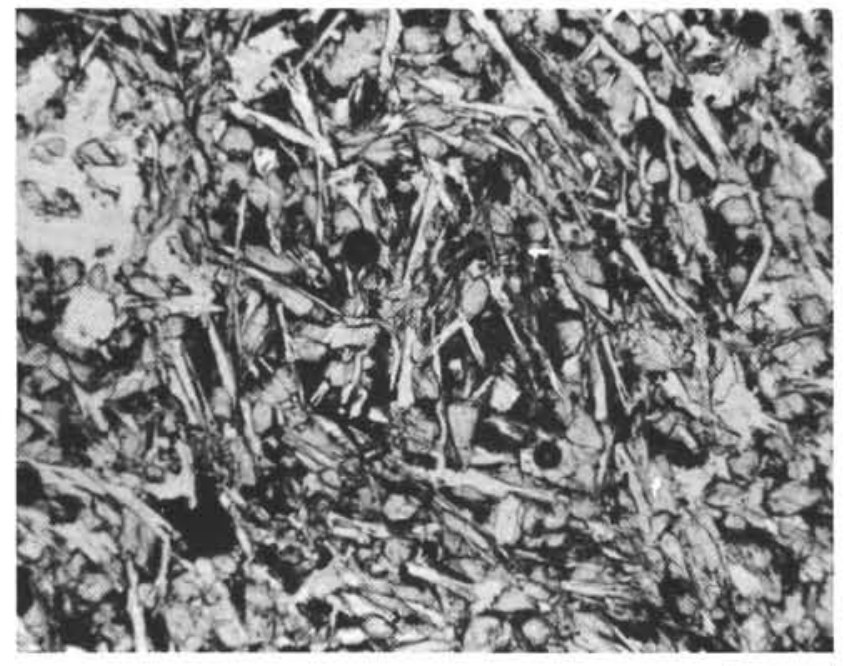

Figure 2. 332A-8-1, \#13c. Basalt with unaltered, magnetite charged glass. Bar scale is $0.1 \mathrm{~mm}$ long. Plane light.

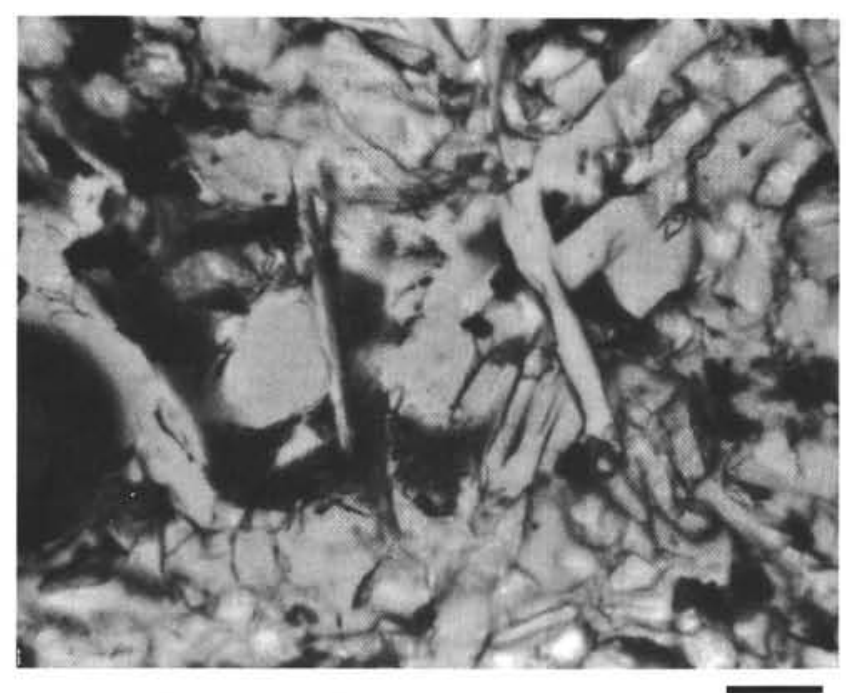

Figure 3. 332A-8-1, \#13c. Vacant round microvesicle in glass. Bar scale is $0.02 \mathrm{~mm}$ long. Plane light.

In the microdoleritic rocks many of the same features prevail, with two main differences. One is the presence of a pale yellow to brown to green low birefringent clay as the main alteration product. This clay is abundant in most, although not all, of the microdoleritic rocks studied; these rocks are commonly highly diktytaxitic, and the clay mainly fills these spaces. The $10 \%$ or so remnant glass is also replaced. There are bands of yellow smectite crossing these rocks; the relationships suggest that the clay is later than the smectite.

Superimposed on this alteration is an oxidation, easily visible by the gray (unoxidized) or brown (oxidized) colors in hand specimen. Oddly enough, this oxidation is not apparent in the thin sections. The oxidation exists adjacent to fractures, without the multiple diffusion bands characteristic of the smectic growth.

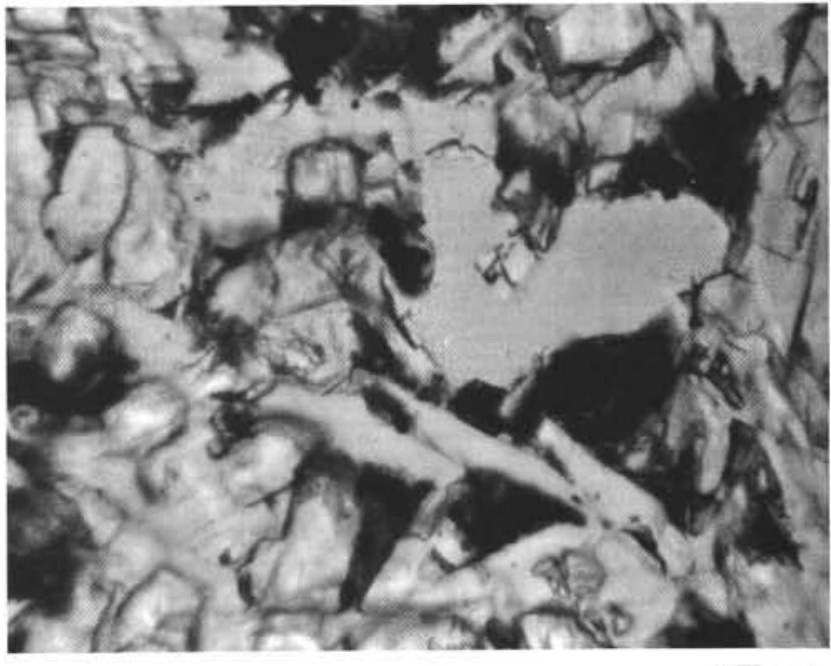

Figure 4. 332A-8-1, \#13c. Vacant irregular microvesicle bounded partly by crystals (pyroxene and plagioclase) and partly by glass. Bar scale is $0.02 \mathrm{~mm}$ long. Plane light.

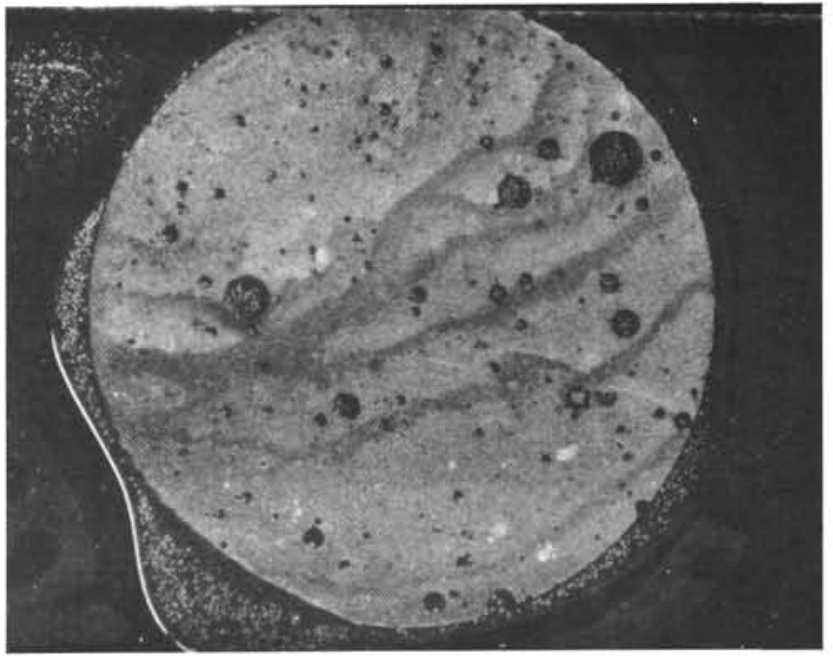

Figure 5. 322A-8-1, \#11. Photomicrograph of the polished section. The irregular, anastomosing bands of smectite (dark-colored bands) show up quite clearly against the lighter, unaltered areas. Diameter of circle approx 25 $\mathrm{mm}$. Reflected light.

\section{GENERAL ALTERATION}

There appear to be five main alteration minerals: siderite(?), calcite (or aragonite), zeolite (possibly two types), smectite, and clay. Figure 9 shows the general paragenetic sequence of all rocks lumped together. There is no apparent change with depth of either minerals present or their amounts or paragenetic sequence.

The siderite(?) occurs as rhombohedral crystals on vesicle walls, mainly in the microdoleritic units. For the most part, the cores are now altered to bright red $\mathrm{Fe}$ oxides, suggesting an iron-rich nature. They are zoned outwards, or rimmed by a syntaxial calcite layer. 


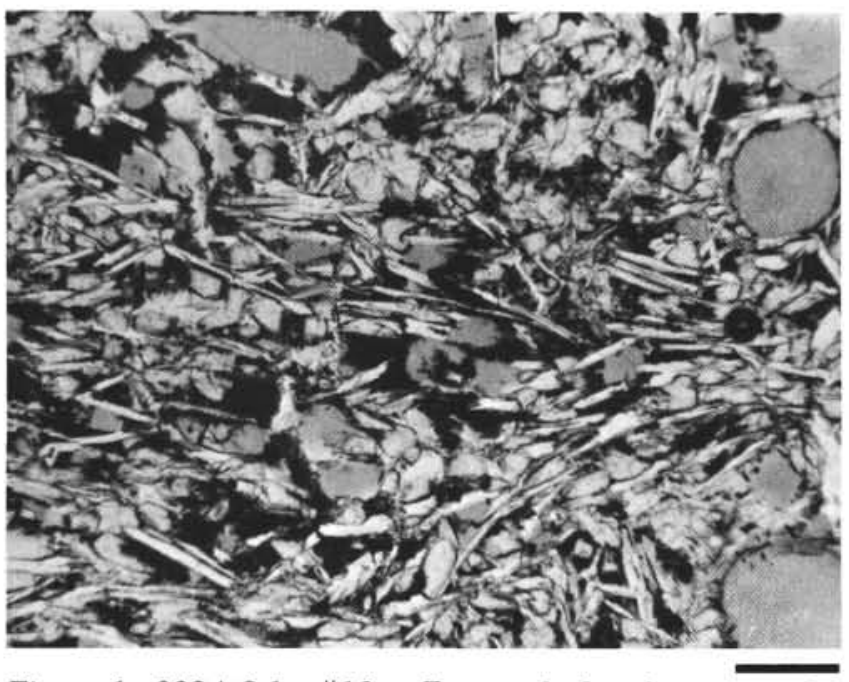

Figure 6. 332A-8-1, \#13c. Zone of abundant smectite. Smectite replaces the glass (dark-colored patches) and fills the microvesicles (pale gray patches). Bar scale is $0.1 \mathrm{~mm}$ long. Plane light.

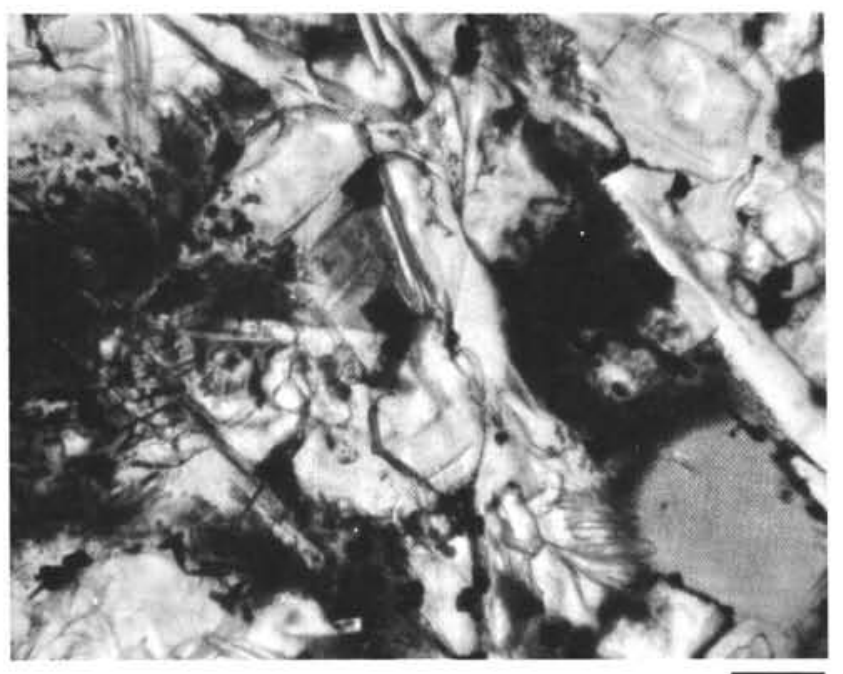

Figure 7. 332A-8-1, \#13c. Globule of smetite in microvesicle in glass. Glass itself is partly altered. This type of texture is strongly reminiscent of chlorophaeite globules in glassy basalts. Bar scale is $0.02 \mathrm{~mm}$ long. Plane light.

The zeolites and many of the radial fibrous carbonate buttons started on the walls of vesicles, but grew simultaneously with smectite (see Figures 10,11). In some situations, the smectite stopped forming before the carbonate, in others it continued until later.

The close control between smectites and fractures and veins suggests that the smectites have formed in response to solutions passing through these fractures Since there appears to be formation of several other minerals prior to the smectite, I would suggest that the smectites have formed after the basalts cooled completely; they are a response of the cold basalt to the seawater circulation system in the pillow basalt pile.

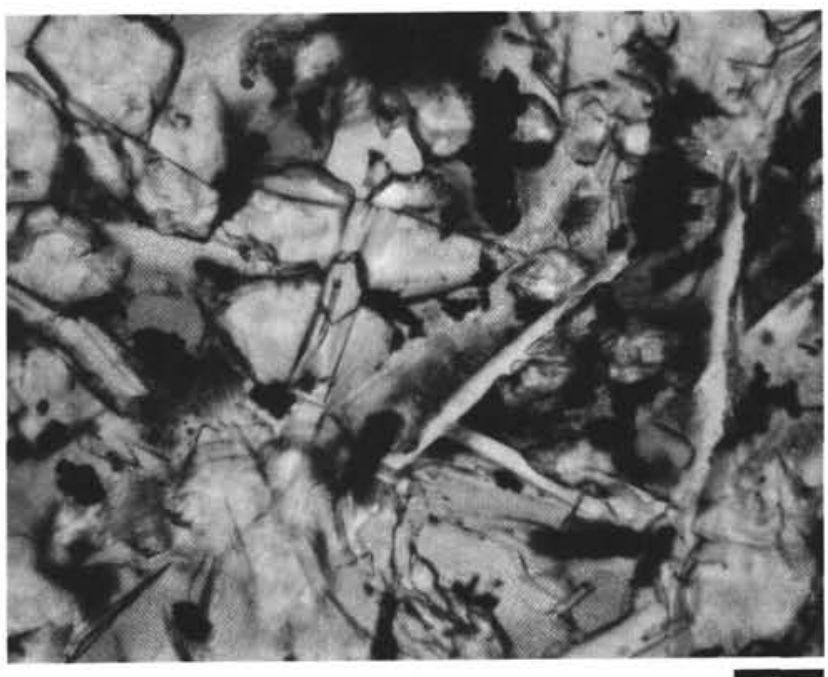

Figure 8. 332A-8-1, \#13c. Gray areas with the skeletal magnetite grains were glass that has been replaced by smectite. Some of the areas show fibers and minute dark brown spots typical of the glass phase. Bar scale is 0.02 mm long. Plane light.

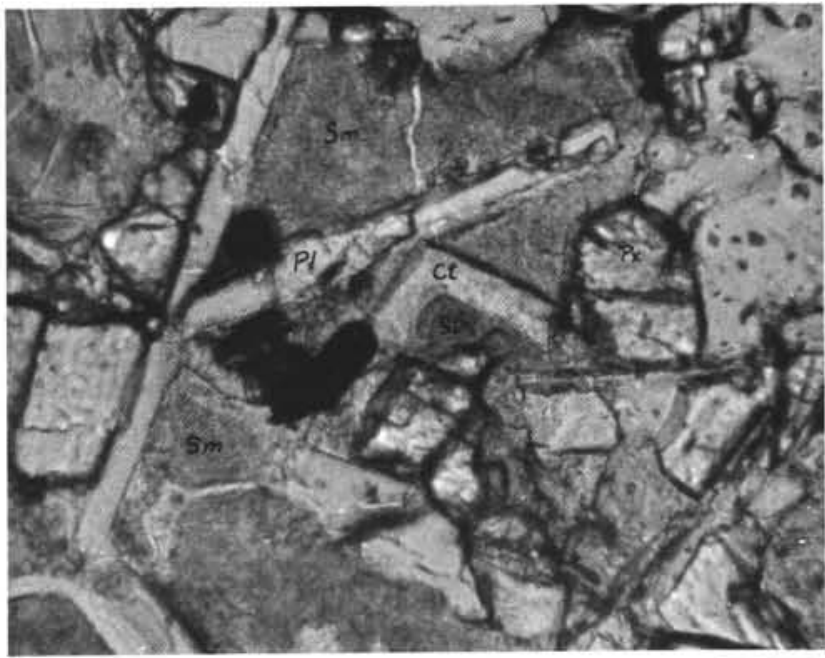

Figure 9. 332A-12-2, \#12F. Siderite (?) (Si) rimmed by calcite $(C t)$, growing in an interstitial microvesicle later filled in with smectite (Sm). Plagioclase (P1) and pyroxene $(P x)$ rim the microvesicle. Bar scale is $0.02 \mathrm{~mm}$ long. Plane light.

Alternative possibilities for the timing are: (1) after the whole stack formed, in which case the P-T gradients within the sampled portion of the pile are insufficient to yield a difference in the style of alteration, or (2) penecontemporaneously with extrusion, the alteration occurring mainly while the basalt was on or very near the surface. Downhole temperatures in Hole $332 \mathrm{~B}$ of $14.9^{\circ} \mathrm{C}$ (Hyndman et al., this volume), and the presence of secondary pyrite veinlets throughout are certainly permissive of either interpretation. 


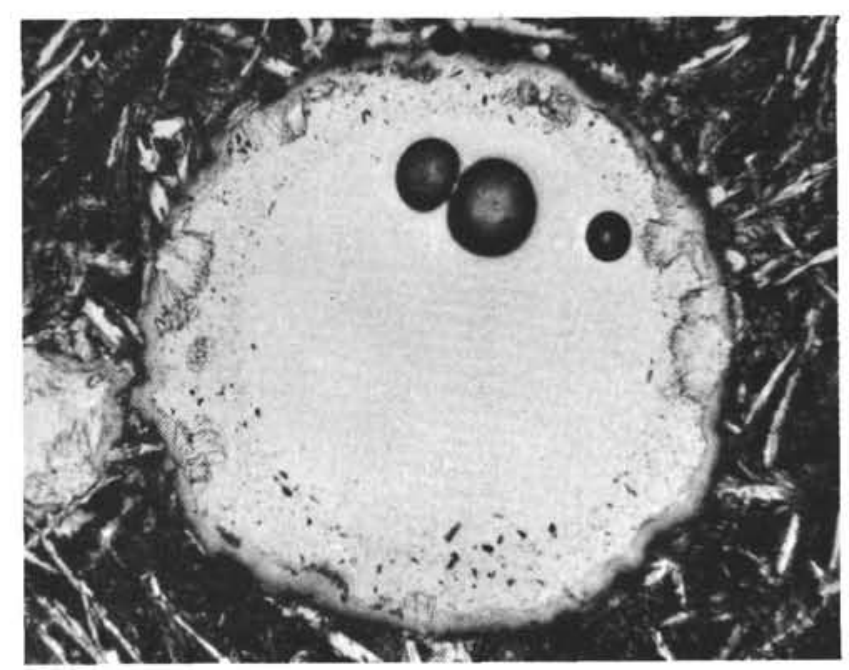

Figure 10. 332A-25-1, \#10a. Vesicle containing radial buttons of very low-birefringent zeolite and a thin rim of smectite. The zeolites seeded on the vesicle rim before the smectite grew, and continued to grow after the smectite ceased. The vesicle is $0.6 \mathrm{~mm}$ in diameter.

\section{SMECTITE SOURCES}

Smectites commonly have between $15 \%$ and $20 \%$ $\mathrm{H}_{2} \mathrm{O}$ (Deer et al, 1962, p. 232-234). Since their specific gravity is also variable between 2 and 3 , one cannot calculate exactly the volume change involved in altering glass or olivine to smectite. Serpentinization of olivine, with no loss of ions, requires a volume expansion of $35 \%$ to $40 \%$ (Thayer, 1966); we might expect similar volume increases during smectite formation, again assuming minimal ionic transport.

Applied to the basaltic rocks of Leg 37, smectites derived in situ should occupy about half again as much space as the original material. Alternatively, any sample that has mostly space-filling smectite must have derived most of that smectite from outside the physical volume of rock being examined.

This paper has described the textural location of smectites within the basalts and pointed out both glass replacement and space-filling positions. Point counts made on selected samples are presented in Table 1. The samples were selected in order to most unequivocally

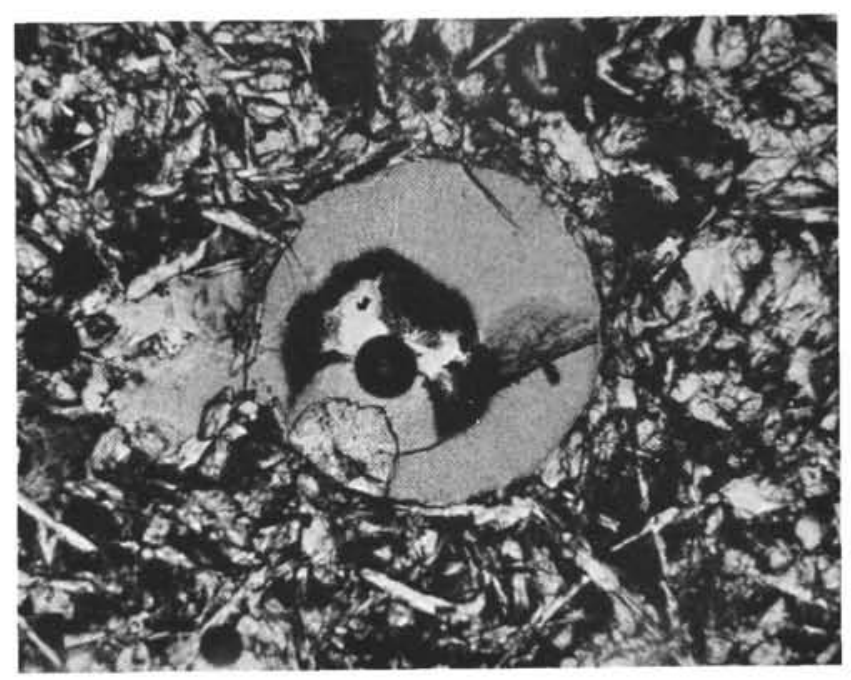

Figure 11. 332A-14-1, \#4. Button of radial fibrous carbonate, which was followed by an infilling of smectite. Vesicle is $0.35 \mathrm{~mm}$ in diameter. Plane light.

show the relative amounts of space filling versus replacement smectite in the rocks. Two of the samples are basalts with variolitic textures, and which had half of the section with abundant smectite, and half essentially unaltered. The other two samples are from one of the microdoleritic units. The samples are separated by $60 \mathrm{~cm}$ in a single core section (possibly much more in original position), with the upper one altered and the lower one "fresh." In fact, the glass of the fresh sample was totally replaced by clay minerals.

The results from all of the rocks show that there is more than twice as much replaced glass as space-filling smectite. Thus there is no need for outside sources to have made a major contribution to the formation of the clay minerals in these rocks. In situ alteration is sufficient.

\section{REFERENCES}

Deer, W.A., Howie, R.A., and Zussman, J., 1962, Rockforming minerals; Sheet silicates; v. 3. London (Longmans).

Thayer, T.P., 1966. Serpentinization considered as a constant volume metasomatic process: Am. Mineral., v. 51, p. 685710 . 
TABLE 1

Modal Analyses of Selected Samples

\begin{tabular}{lcc|cc|cc}
\hline & \multicolumn{2}{c|}{$\begin{array}{c}32 \mathrm{~A}-8-1, \\
123 \mathrm{~cm}\end{array}$} & \multicolumn{2}{c|}{$\begin{array}{c}32 \mathrm{~A}-9-1, \\
50 \mathrm{~cm}\end{array}$} & \multicolumn{2}{c}{$332 \mathrm{~A}-12-2$} \\
\cline { 2 - 7 } & Fresh & Altered & Fresh & Altered & $\begin{array}{c}\text { Fresh } \\
(84 \mathrm{~cm})\end{array}$ & $\begin{array}{c}\text { Altered } \\
(20 \mathrm{~cm})\end{array}$ \\
\hline Plagioclase & 34 & 30 & 27 & 28 & 40 & 43 \\
Pyroxene & 36 & 35 & 40 & 40 & 36 & 33 \\
Opaques & 5 & 5 & 6 & 6 & 3 & 1 \\
Open vesicles & 5 & 2 & 3 & - & 3 & - \\
Smectite in vesicles & - & 4 & - & 2 & 3 & - \\
Open microvesicles & 5 & - & 3 & - & - & - \\
Smectite in microvesicles & - & 3 & - & 2 & - & - \\
Unaltered glass & 15 & - & 20 & - & 21 & $20^{\mathrm{a}}$ \\
Altered glass & - & 21 & - & -
\end{tabular}

Note: Analyses show the relative proportions of replacement vs. space-filling smectite. $332 \mathrm{~A}-8-1,123 \mathrm{~cm}$ and $332 \mathrm{~A}-9-1,50 \mathrm{~cm}$ have typical fine-grained basaltic textures with scattered variolites; the $332 \mathrm{~A}-12-2$ samples are from a microdoleritic unit. The basaltic slides were chosen because these slides had fresh and altered rock in the same slide. For the microdoleritic rocks, samples $60 \mathrm{~cm}$ apart (in the recovered core) had to be used.

${ }^{a}$ Unable to distinguish in many cases between smectite from glass or smectite filling microvesicles. 